\title{
Electrochemical and quantum chemical study to assess the role of (2E)-2-(furan-2-ylmethylidene) hydrazine carbothioamide as inhibitor for acid corrosion of mild steel
}

\author{
V. R. Adinarayanan ${ }^{1}$ · P. Preethi Kumari ${ }^{1} \cdot$ Suma A. Rao $^{1}$ (D)
}

Received: 10 August 2021 / Accepted: 24 October 2021 / Published online: 27 December 2021

(c) The Author(s) 2021

\begin{abstract}
Synthesis and inhibition effectiveness of (2E)-2-(furan-2-ylmethylidene) hydrazine carbothioamide (FMHC) as an inhibitor for corrosion of mild steel in $0.5 \mathrm{M} \mathrm{H}_{2} \mathrm{SO}_{4}$ is reported. Experiments were conducted at various temperatures (303-323 K) by adopting potentiodynamic polarization and electrochemical impedance spectroscopy. Readings obtained demonstrated that percentage inhibition efficiency (\% IE) improved with the upsurge in the concentration of FMHC, while it decreased with a rise in temperature. The highest $\%$ IE observed was $60 \%$ for $2.5 \times 10^{-4} \mathrm{M}$ FMHC at $303 \mathrm{~K}$. FMHC worked moderately as a mixed inhibitor. FMHC obeyed the Langmuir model of adsorption and the mode of adsorption was physisorption on the mild steel surface which was further endorsed by examining the surface using the scanning electron microscope. A clear insight into the mechanistic features of corrosion inhibition by using FMHC was acquired. Calculation of activation parameters helped to suggest an appropriate mechanism for the adsorption of FMHC on mild steel through quantum chemical calculations using density functional theory (DFT).
\end{abstract}

\section{Graphical abstract}

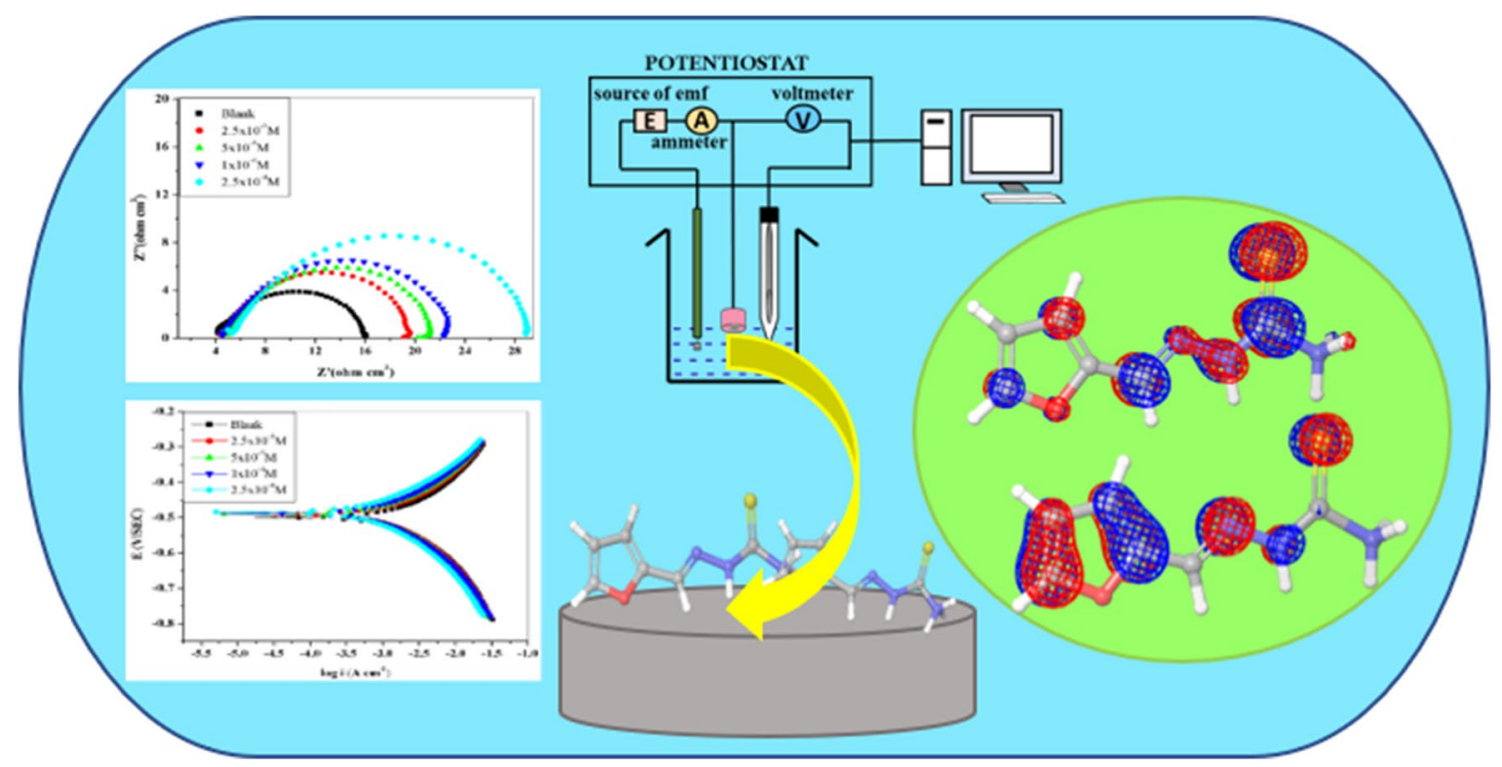

Keywords Mild steel $\cdot$ Hydrazine carbothioamide $\cdot$ Physisorption $\cdot$ Adsorption $\cdot$ Surface morphology $\cdot$ Density functional theory

Extended author information available on the last page of the article 


\section{Introduction}

Mild steel due to its outstanding mechanical properties such as high tensile strength, impact strength, easy availability, low price is used in diverse industries such as construction or structural material, in chemical reactors, oil, and gas transport pipelines, manufacturing of automobiles, etc. [1]. The most commonly used acid solutions for removal of rust, de-scaling, and pickling before plating are hydrochloric acid and sulphuric acid [2]. Mild steel undergoes corrosion when exposed to acidic environments and hence their surface must be protected. Protection of metals from corrosion is important as corrosion leads to a great loss of material, as well as economy. The consequence of corrosion is tremendous, and its inhibition has been profoundly examined. It has been tracked down that perhaps the best strategy for protecting materials against electrochemical degradation includes the addition of inhibitors that are substances that minimize the rate of corrosion [3]. Subsequently, in the field of corrosion and industry, there is always a need to develop and use corrosion inhibitors which are an effective and reasonably lowcost method, to minimize the corrosive damage on materials. Literature reports indicated that usually compounds comprising of heteroatoms, unsaturated bonds, and aromatic or heterocyclic rings performed as inhibitors [4, 5]. Adsorption of inhibitor molecules on a material surface is responsible for corrosion inhibition. The adsorption relies fundamentally upon the electronic structure of the molecule. The effectiveness of the inhibitor relies upon its structure and the type of interaction with the metal surface [6].

To alleviate corrosion of mild steel in acid medium, hydrazide derivatives [7-11], thiosemicarbazide derivatives, acid hydrazide derivatives, and hydrazone derivatives [12-15] are reported. This is because of their exceptional structural features. The planarity of the whole structure of the compound dictates the formation of an adsorption film on the metal. [16]. As a part of our work on corrosion inhibition, we hereby report the corrosion rates of mild steel in $0.5 \mathrm{M} \mathrm{H}_{2} \mathrm{SO}_{4}$, determined by electrochemical techniques and its inhibition by (2E)-2-[Furan-2-ylmethylidene] hydrazine carbothioamide (FMHC) at three different temperatures. The synthesized inhibitor possesses a linear structure with active centers like heteroatoms, electron-donating groups, etc., which is the major requirement of efficient inhibitor.

\section{Experimental details}

\subsection{Material}

The composition of the test coupon of mild steel utilized for corrosion study is given in Table 1.

\subsection{Test specimen preparation}

The mild steel test specimen was readied by means of cold setting resin. The uncovered level surface $\left(1 \mathrm{~cm}^{2}\right)$ of the mounted part was subjected to polishing with different coarseness levels of emery papers and later the surface was finished by disc polishing with levigated alumina. Test coupon was washed with water, acetone and dried.

\subsection{Preparation of medium}

The stock of $1 \mathrm{M}$ solution of $\mathrm{H}_{2} \mathrm{SO}_{4}$ was prepared from AR $\mathrm{H}_{2} \mathrm{SO}_{4}$. The solution was standardized by volumetric titration. As and when required from the stock, by proper dilution, the desired concentration was prepared.

\subsection{Synthesis of (2E)-2-(furan-2-ylmethylidene) hydrazine carbothioamide (FMHC)}

As per the reported literature, [17] (2E)-2-(furan-2-ylmethylidene) hydrazine carbothioamide (FMHC) was synthesized. An equimolar mixture of furan-2-aldehyde and thiosemicarbazide with sulphuric acid was refluxed on a boiling water bath for around $4 \mathrm{~h}$. Ethanol was used for the recrystallization of the precipitated product. The scheme for the preparation of FMHC is given in Fig. 1. The characterization was done by IR and spectra is shown in Fig. 2 .
Table 1 Composition of specimen

Fig. 1 Synthetic route for FMHC

\begin{tabular}{llllllllllll}
\hline Element & $\mathrm{C}$ & $\mathrm{Si}$ & $\mathrm{Mn}$ & $\mathrm{P}$ & $\mathrm{S}$ & $\mathrm{Cr}$ & $\mathrm{Ni}$ & $\mathrm{Mo}$ & $\mathrm{Al}$ & $\mathrm{Cu}$ & $\mathrm{Fe}$ \\
\hline (\%wt.), & 0.169 & 0.188 & 0.414 & 0.060 & 0.042 & 0.020 & 0.028 & 0.018 & 0.004 & 0.072 & Balance \\
\hline
\end{tabular}

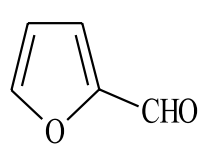

furan-2-aldehyde<smiles>NNC(N)=S</smiles>

Thiosemicarbazide

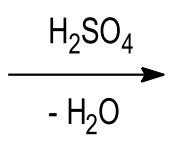<smiles>NC(=S)N/N=C/c1ccco1</smiles>

(2E)-2-(furan-2-ylmethylidene)hydrazinecarbothioamide 
Fig. 2 IR spectra of FMHC. $\mathrm{C}_{6} \mathrm{H}_{7} \mathrm{~N}_{3} \mathrm{OS}$ m. p: $230-232{ }^{\circ} \mathrm{C}$ IR (KBr) $\left[\mathrm{cm}^{-1}\right]: 3255.95(\mathrm{OH}$ str.), 3186 (NH str.), 3035 (Ar. CH str. $), 1614(\mathrm{C}=\mathrm{O}), 1600$ $(\mathrm{C}=\mathrm{N}$ str. $)$, and 1600 (Ar. $\mathrm{C}=\mathrm{C}$ str. $)$

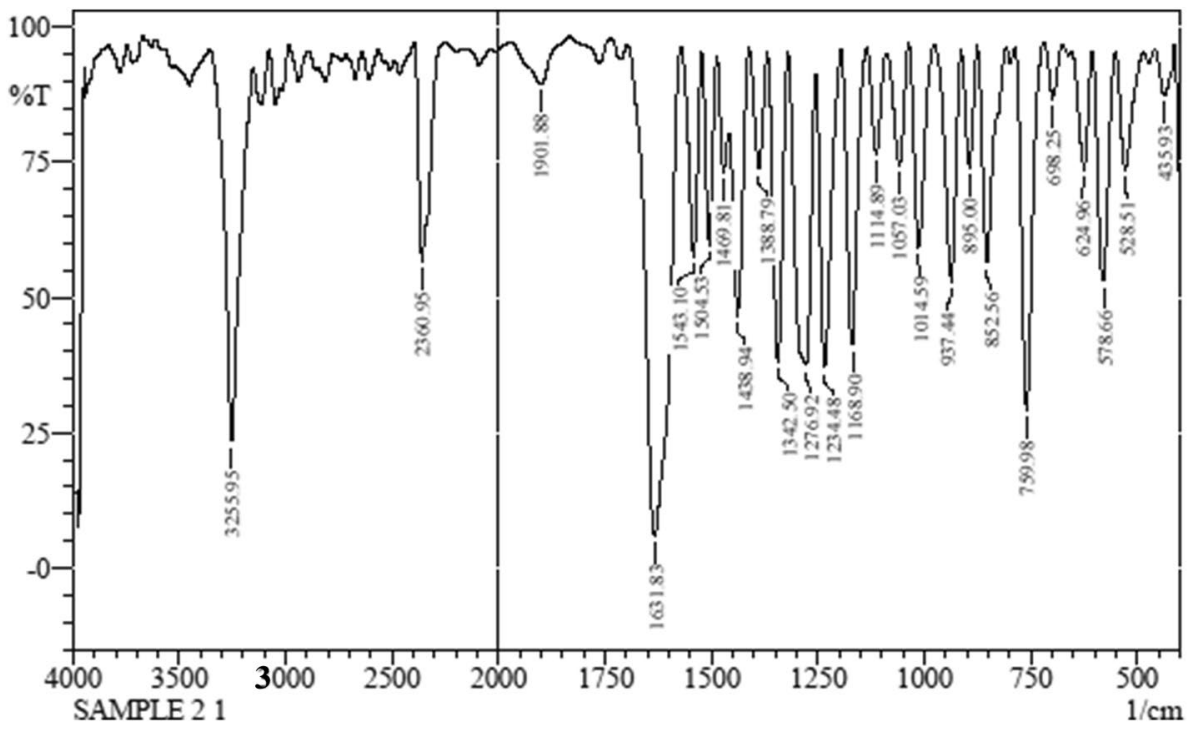

\subsection{Electrochemical studies}

Electrochemical examinations were performed with a potentiostat (USA Model 604D with beta programming). Pyrex glass cell with 3 electrodes, namely, counter (platinum), saturated calomel reference electrode (SCE), and the working electrode (mild steel) was used. A finely polished mild steel test coupon was introduced to $0.5 \mathrm{M}$ sulphuric acid in the absence and presence of the inhibitor at various temperatures (303-323 K) and endorsed to establish an open circuit potential (OCP). PDP plots were recorded by drifting the potential of the test specimen to $-250 \mathrm{mV}$ cathodically and $+250 \mathrm{mV}$ anodically with respect to the OCP for a sweep speed of $0.5 \mathrm{mV} \mathrm{s}^{-1}$ [18]. The impedance tests were done by applying in the periodic $\mathrm{AC}$ signal of $10 \mathrm{mV}$ in the wide frequency range of $100 \mathrm{kHz}$ to $0.01 \mathrm{~Hz}$ on the OCP [19].

\subsection{Surface studies}

Scanning electron microscopy (SEM) images of test specimen were noted using (JEOL JSM-6380 L) scanning electron microscope. The surface of the corroded sample was studied by dipping it in $0.5 \mathrm{M}$ sulphuric acid solution for $3 \mathrm{~h}$ in absence and presence of FMHC.

\subsection{Quantum chemical calculations}

Schrodinger programming (Maestro Material Science) was utilized to do quantum chemical estimations. The DFT was used to optimize the geometry of inhibitor FMHC. Computations were done using the Hybrid functional with the correlation functional (B3LYP) and 6-31G** as the basis set. For neutral and protonated FMHC, frontier molecular orbital (FMO) energies were determined and explained in depth.
Distinctive hypothetical parameters like the energy gap $(\Delta \mathrm{E})$, hardness $(\eta)$, softness $(\sigma)$, electronegativity $(\chi)$, electrophilicity $(\omega)$, nucleophilicity $(\varepsilon)$, and portion of electron transferred $(\Delta \mathrm{N})$ were assessed utilizing appropriate equations [20-22]. Mulliken charge population was assessed. The dipole moment of protonated and neutral FMHC was found and compared.

\section{Results and discussion}

\subsection{Potentiodynamic polarization studies}

The potentiodynamic polarization graphs for mild steel in $0.5 \mathrm{M} \mathrm{H}_{2} \mathrm{SO}_{4}$ at $313 \mathrm{~K}$ without and with the addition of FMHC are shown in Fig. 3. Electrochemical parameters such as corrosion potential $\left(E_{\text {corr }}\right)$, corrosion current density $\left(i_{\text {corr }}\right)$, cathodic slope $\left(-\beta_{\mathrm{c}}\right)$, and anodic slope $\left(\beta_{\mathrm{a}}\right)$ were noted and corrosion rate (CR) and percentage inhibition efficiency (\%IE) were calculated [23] using Eqs. (1) and (2), respectively.

$\mathrm{CR}\left(\mathrm{mmy}^{-1}\right)=\frac{3270 \times M \times i_{\text {corr }}}{d \times n}$

$I E \%=\left(\frac{i_{\text {corr }}-i_{\text {corr }(i n h)}}{i_{\text {corr }}}\right) \times 100$

$i_{\text {corr }}$ and $i_{\text {corr(inh) }}$ are corrosion current density $\left(\mu \mathrm{A} \mathrm{cm}^{-2}\right)$ in the absence and presence of the inhibitor, 3270 is a constant, $M$ is the atomic mass of corroding material [55.85], $d=$ density of corroding material $\left(7.725 \mathrm{~g} \mathrm{~cm}^{-3}\right)$, and $\mathrm{n}$ is the 


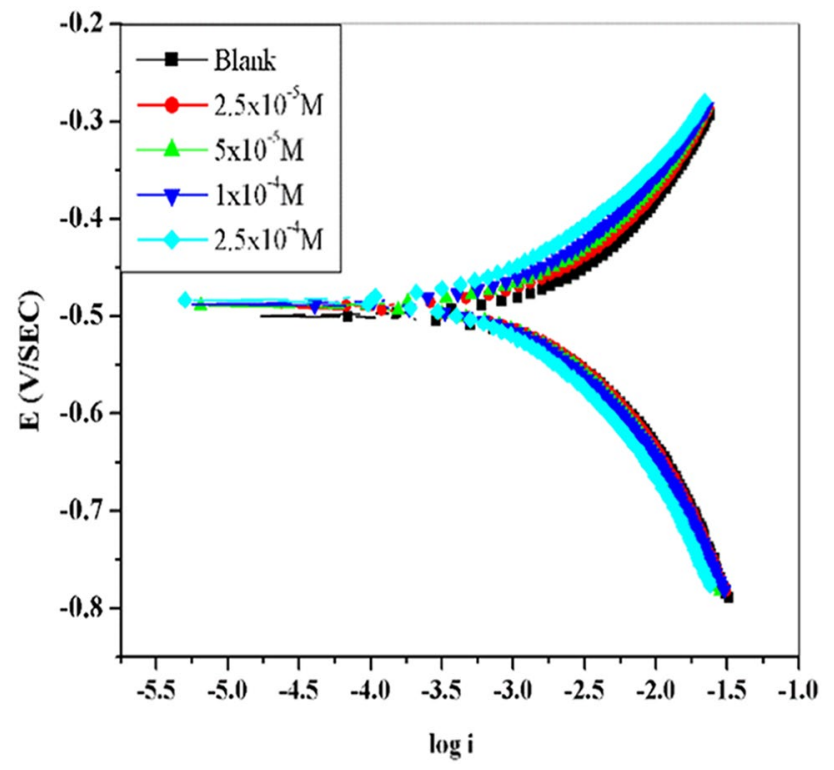

Fig. 3 PDP plot for corrosion of mild steel in presence of diverse FMHC concentrations in $0.5 \mathrm{M} \mathrm{H}_{2} \mathrm{SO}_{4}$ at $313 \mathrm{~K}$

number of electrons involved in the reaction $(n=2)$. Fraction of surface covered $(\theta)$ is calculated using Eq. (3)

$\% \mathrm{IE}=\theta \times 100$

From Fig. 3, it was seen that the corrosion potential does not shift much with respect to blank. The slight difference in the cathodic and anodic slope shows the influence of the inhibitor FMHC on the reaction kinetics but not on the mechanism $[24,25]$. The results of Tafel polarization are tabulated in Table 2.
From Table 2 it is evident that the corrosion rate of mild steel amplified with the upsurge in temperature in absence of FMHC. Added FMHC lessened the rate of corrosion. IE decreased with an increase in temperature. The exothermic nature of the adsorption process is suggestive of physical adsorption [26].

\subsection{Electrochemical impedance spectroscopy}

The Nyquist plot for the corrosion of mild steel in $0.5 \mathrm{M}$ $\mathrm{H}_{2} \mathrm{SO}_{4}$ is shown in Fig. 4. The plot consists of two loops. One loop is high-frequency (HF) capacitive loop and another is small inductive loop at medium frequency (MF). Capacitive loop at high frequency stands for resistance for charge transfer. Diameter of the capacitive loop increased after the addition of inhibitor and increased further with increase in concentration of inhibitor. It clearly demonstrated the ability of inhibitor molecule to bring down the rate of charge transfer and hence corrosion [27]. Small inductive loop could be due to relaxation effect either due to hydrogen ion or corrosion product or metal ion inhibitor complex.

The appropriate equivalent circuit was used to simulate the impedance data with FMHC as shown in Fig. 4b. It consisted of 5 elements. They are solution resistance $\left(R_{\mathrm{s}}\right)$, charge transfer resistance $\left(R_{\mathrm{ct}}\right)$, time constant phase element $(Q)$, an inductive element $(\mathrm{L})$, and inductive resistance $\left(R_{\mathrm{L}}\right)$ [28].

The collective resistance due to the charge transfer and inductive loop is considered polarization resistance $\left(R_{\mathrm{p}}\right)$. It is calculated as per Eq. (4)

Table 2 Results of PDP measurements

\begin{tabular}{|c|c|c|c|c|c|c|c|}
\hline Temp (K) & $\mathrm{FMHC} \times 10^{-5}(\mathrm{M})$ & $\mathrm{E}_{\text {corr }}(\mathrm{mV})$ & $-\beta_{\mathrm{c}}\left(\mathrm{mVdec}{ }^{-1}\right)$ & $\beta_{\mathrm{a}}\left(\mathrm{mVdec}^{-1}\right)$ & $\mathrm{CR}\left(\mathrm{mmy}^{-1}\right)$ & $i_{\text {corr }}\left(\mathrm{mA} \mathrm{cm}^{-2}\right)$ & IE $(\%)$ \\
\hline \multirow[t]{5}{*}{303} & 0.0 & -499 & 71.69 & 71.32 & 7.437 & 1.259 & 0 \\
\hline & 2.5 & -492 & 66.37 & 72.70 & 6.017 & 1.018 & 19.14 \\
\hline & 5.0 & -490 & 72.27 & 77.11 & 4.932 & 0.834 & 33.68 \\
\hline & 10.0 & -486 & 74.38 & 81.42 & 4.630 & 0.783 & 37.73 \\
\hline & 25.0 & -481 & 75.39 & 88.91 & 2.946 & 0.448 & 60.00 \\
\hline \multirow[t]{5}{*}{313} & 0.0 & -497 & 68.04 & 66.08 & 10.871 & 1.840 & 0 \\
\hline & 2.5 & -491 & 73.24 & 70.62 & 8.133 & 1.518 & 17.50 \\
\hline & 5.0 & -490 & 75.09 & 74.16 & 7.366 & 1.247 & 32.22 \\
\hline & 10.0 & -486 & 78.16 & 75.50 & 6.911 & 1.170 & 36.41 \\
\hline & 25.0 & -480 & 77.09 & 82.61 & 4.505 & 0.762 & 58.00 \\
\hline \multirow[t]{5}{*}{323} & 0.0 & -497 & 63.88 & 61.78 & 14.216 & 2.406 & 0 \\
\hline & 2.5 & -491 & 56.97 & 63.65 & 13.423 & 2.105 & 12.48 \\
\hline & 5.0 & -488 & 63.17 & 68.03 & 12.440 & 1.675 & 30.38 \\
\hline & 10.0 & -492 & 67.33 & 71.18 & 9.362 & 1.585 & 34.12 \\
\hline & 25.0 & -480 & 67.39 & 76.83 & 8.453 & 1.328 & 44.80 \\
\hline
\end{tabular}




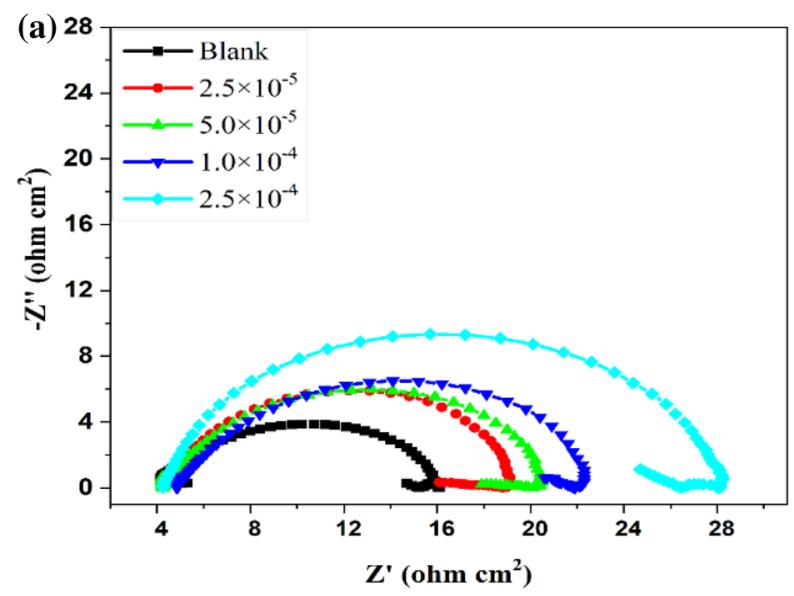

Fig. 4 a Nyquist plots and b equivalent circuit fitment

$R_{\mathrm{p}}=\frac{R_{\mathrm{ct}} \times R_{\mathrm{L}}}{R_{\mathrm{ct}}+R_{\mathrm{L}}}$

The increase in the concentration of inhibitor added tends to decrease the double-layer capacitance $\left(\mathrm{C}_{\mathrm{dl}}\right)$ because of the decrease in the double-layer thickness [29]. CPE acts as an ideal double-layer capacitance $\left(C_{\mathrm{dl}}\right)$. It was calculated from the frequency $\left(f_{\max }\right)$ at which the imaginary component of impedance becomes maximum (Zimp, max) using Eq. (5)

$C_{\mathrm{dl}}=\frac{1}{2 \pi R_{\mathrm{ct}} f_{\max }}$

Calculation of percentage inhibition was done using Eq. (6)

$\mathrm{IE}(\%)=\frac{R_{\mathrm{ct}(\mathrm{inh})-} R_{\mathrm{ct}}^{0}}{R_{\mathrm{ct}(\mathrm{inh})}}$

where $R_{\mathrm{ct}}$ and $R_{\mathrm{ct}}^{0}$ show the charge transfer resistance in the presence and absence of inhibitor. Results are tabularized in Table 3

It is evident from Table 3 that the $C_{\mathrm{dl}}$ values decreased with a rise in inhibitor concentration at all studied temperatures. Increased $R_{\mathrm{ct}}$ values at increased concentrations of FMHC resulted in improved corrosion resistance. This suggests the presence of a barrier layer on the electrode surface. The results obtained by the PDP and EIS method for the corrosion of mild steel in $0.5 \mathrm{M} \mathrm{H}_{2} \mathrm{SO}_{4}$ with FMHC were in good agreement at all studied temperatures.

\subsection{Effect of temperature}

Influence of temperature on the corrosion rate of mild steel and inhibition efficiency of inhibitor was studied at temperatures range of $303 \mathrm{~K}$ to $323 \mathrm{~K}$. Figure 5 depicts the

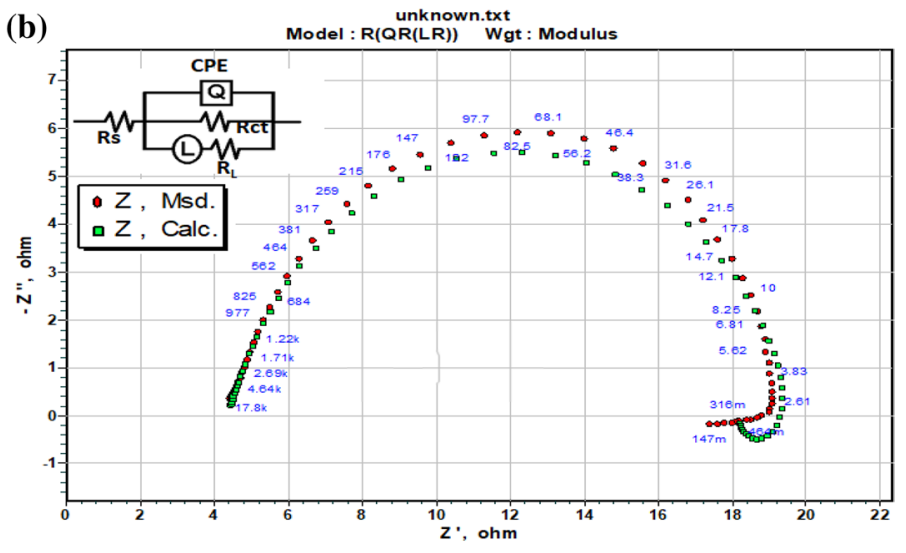

variation of \% IE at varying concentrations of FMHC at different temperatures.

Using Arrhenius equation (Eq. 7), calculation of the activation energy $\left(\mathrm{E}_{\mathrm{a}}\right)$ was done

$\ln (\mathrm{CR})=B-\frac{E_{\mathrm{a}}}{R T}$

where $B=$ Arrhenius pre-exponential constant and $R=$ universal gas constant.

The slope of the plot of ln CR vs 1/T (Fig. 6a) [30] is used to calculate the activation energy. Enthalpy of activation $\left(\Delta H_{\mathrm{a}}\right)$ and entropy of activation $\left(\Delta S_{\mathrm{a}}\right)$ were found out using the transition state Eq. (8)

$\mathrm{CR}=\frac{R T}{N h} \exp \left(\frac{\Delta S^{\#}}{R T}\right) \exp \left(\frac{-\Delta H^{\#}}{R T}\right)$

Here $h$ is Planck's constant and $N$ is Avogadro's number. Plot of $\ln (\mathrm{CR} / T)$ vs $1 / T$ [Fig. 6b] gave a straight line. From slope and intercept, activation parameters were evaluated and recorded in Table 4.

The increase in activation energy indicates an increase in the energy barrier for the corrosion reaction. $E_{\mathrm{a}}$ values increased with an increase in FMHC concentration suggesting the physisorption. The negative value of entropy of activation $\left(\Delta S_{\mathrm{a}}\right)$ indicates the association process during the formation of the activated complex [31, 32].

\subsection{Adsorption isotherm}

Adsorption isotherm provides evidence for interaction among inhibitor and metal surface. It enables the understanding of the mechanism of corrosion inhibition. FMHC adsorbs on the metal surface and forms a barricade over it and isolates the metal surface from the medium. The efficiency of the inhibitor 
Table 3 Results of EIS measurements

\begin{tabular}{lllllll}
\hline Temp. (K) & $\begin{array}{l}\text { FMHC } \times 10^{-5} \\
(\mathrm{M})\end{array}$ & $\mathrm{R}_{\mathrm{ct}}\left(\Omega \mathrm{cm}^{-2}\right)$ & $\mathrm{R}_{\mathrm{L}}\left(\Omega \mathrm{cm}^{-2}\right)$ & $\mathrm{R}_{\mathrm{p}}\left(\Omega \mathrm{cm}^{-2}\right)$ & $\mathrm{C}_{\mathrm{dl}}\left(\mu \mathrm{F} \mathrm{cm} \mathrm{cm}^{2}\right)$ & $\mathrm{IE}(\%)$ \\
\hline 303 & 0.0 & 16.74 & 118.9 & 14.67 & 1033.7 & - \\
& 2.5 & 20.11 & 162.1 & 17.89 & 679.43 & 18.00 \\
& 5.0 & 22.50 & 219.4 & 20.41 & 440.84 & 28.11 \\
& 10.0 & 27.20 & 251.8 & 24.55 & 285.76 & 40.24 \\
& 25.0 & 50.20 & 295.0 & 42.90 & 123.32 & 65.80 \\
& 0.0 & 12.13 & 84.63 & 10.61 & 3032.1 & - \\
& 2.5 & 14.37 & 114.4 & 12.77 & 2362.3 & 16.90 \\
& 5.0 & 16.54 & 115.9 & 14.47 & 1842.7 & 26.70 \\
& 10.0 & 19.01 & 120.2 & 16.41 & 1481.0 & 35.36 \\
& 25.0 & 23.75 & 268.7 & 21.82 & 774.66 & 51.38 \\
& 0.0 & 10.15 & 67.57 & 8.82 & 4748.6 & - \\
& 2.5 & 11.35 & 75.20 & 9.86 & 3588.2 & 10.52 \\
& 5.0 & 13.51 & 98.65 & 11.88 & 2617.3 & 25.74 \\
& 10.0 & 15.02 & 105.2 & 13.14 & 2096.1 & 32.86 \\
& 25.0 & 18.26 & 145.6 & 16.23 & 1603.6 & 45.61 \\
\hline
\end{tabular}

depends on the degree of surface coverage $(\theta)$. Linear fit of parameters to several adsorption isotherms in the temperature range was considered, and Langmuir's adsorption isotherm was obeyed. It is given by the expression (9)

Table 4 Activation parameters

\begin{tabular}{llll}
\hline $\begin{array}{l}\mathrm{FMHC} \times 10^{-5} \\
(\mathrm{M})\end{array}$ & $E_{\mathrm{a}}\left(\mathrm{kJ} \mathrm{mol}^{-1}\right)$ & $\Delta \mathrm{H}_{\mathrm{a}}\left(\mathrm{kJ} \mathrm{mol}^{-1}\right)$ & $\begin{array}{l}-\Delta S_{\mathrm{a}}(\mathrm{J} \\
\left.\mathrm{K}^{-1} \mathrm{~mol}^{-1}\right)\end{array}$ \\
\hline 0 & 26.39 & 23.79 & 149.61 \\
2.5 & 32.54 & 29.94 & 131.50 \\
5.0 & 37.57 & 34.97 & 116.48 \\
10.0 & 28.67 & 26.07 & 146.05 \\
25.0 & 42.77 & 40.17 & 103.70 \\
\hline
\end{tabular}

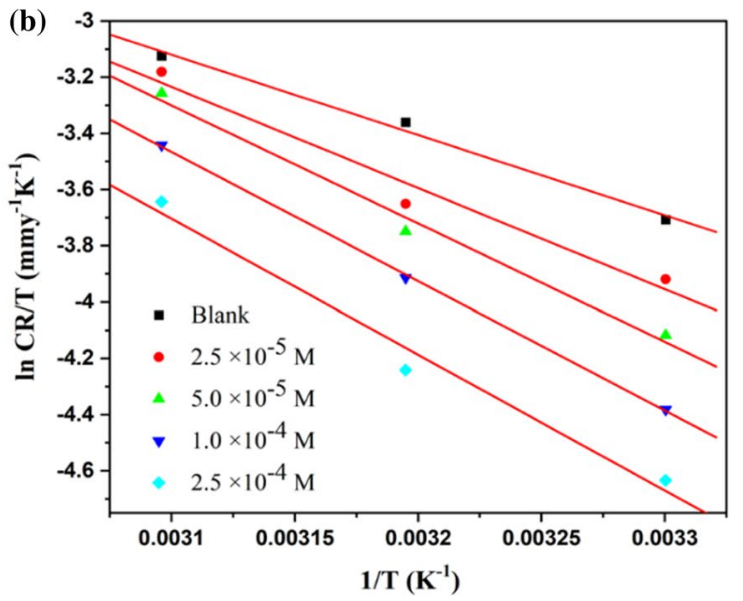

Fig. 6 Plot of $\mathbf{a} \ln (\mathrm{CR}) \mathrm{Vs}(1 / T)$ and $\mathbf{b} \ln (\mathrm{CR} / \mathrm{T})$ vs $1 / T$ 


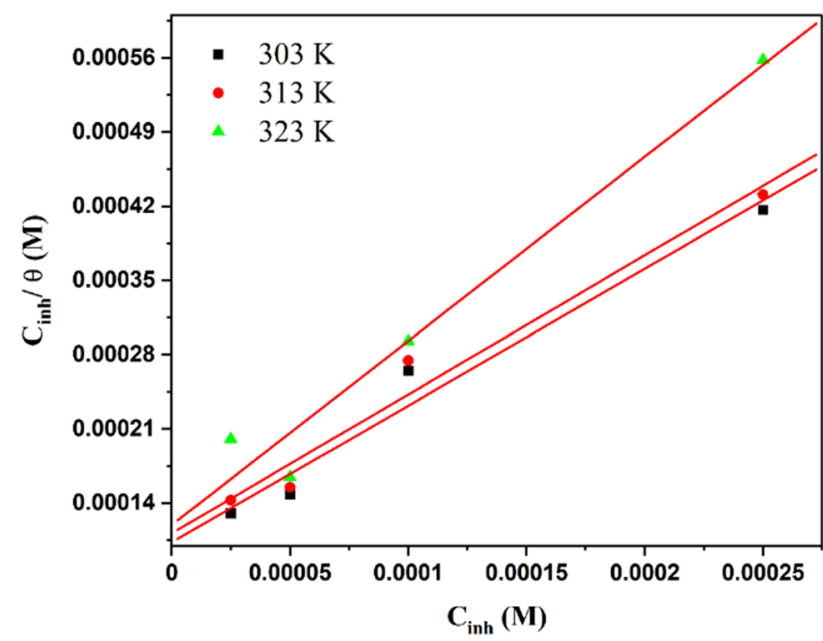

Fig. 7 Langmuir adsorption isotherm

$\frac{C_{\mathrm{inh}}}{\theta}=\frac{1}{K}+C_{\mathrm{inh}}$

where the $K$ value indicates the equilibrium constant for metal-inhibitor interaction, $C_{\text {inh }}$ is the inhibitor concentration, and $\theta$ is the degree of surface coverage [33]. The plots of $C_{\text {inh }} / \theta$ versus $C_{\text {inh }}$ for different temperatures give a straight line with intercept $1 / K$ as shown in Fig. 7

Standard free energy of adsorption $\left(\Delta G_{\text {ads }}^{0}\right)$ is related to adsorption/desorption constant $(K)$ by relation (10)

$K=\frac{1}{55.5} \exp \left(\frac{-\Delta G_{\mathrm{ads}}^{0}}{R T}\right)$

where $R$ is the universal gas constant, $T$ is absolute temperature, and 55.5 is the concentration of water in solution in $\mathrm{mol} \mathrm{dm}^{-3}$ [34].

As per the reported literature $[35,36] \Delta G_{\text {ads }}^{0}$ more negative than $-40 \mathrm{~kJ} \mathrm{~mol}^{-1}$ is suggestive of chemical adsorption. However, in the present study value of $\Delta G_{\text {ads }}^{0}$ is found to be between $-33 \mathrm{~kJ} \mathrm{~mol}^{-1}$ and $-35 \mathrm{~kJ} \mathrm{~mol}^{-1}$. It is clearly suggestive of physical adsorption. In order to get a clear-cut picture of the nature of adsorption, detailed quantum chemical calculations are done and discussed in Sect. 3.6

\subsection{Role of FMHC in corrosion inhibition}

Adsorption of FMHC is a consequence of the replacement of water molecules which is usually adsorbed on the metal surface.

$\mathrm{Inh}_{(\mathrm{sol})}+n \mathrm{H}_{2} \mathrm{O}_{(\mathrm{ads})} \leftrightarrow \mathrm{Inh}_{(\mathrm{ads})}+n \mathrm{H}_{2} \mathrm{O}_{(\mathrm{sol})}$

$6 \mathrm{H}_{2} \mathrm{SO}_{4}+3 \mathrm{Fe} \rightarrow 3 \mathrm{Fe}\left(\mathrm{HSO}_{4}\right)_{2}+3 \mathrm{H}_{2}$

$3 \mathrm{Fe}\left(\mathrm{HSO}_{4}\right)_{2} \rightarrow \mathrm{Fe}_{3}\left(\mathrm{SO}_{4}\right)_{2}+4 \mathrm{H}_{2} \mathrm{SO}_{4}$

The metal surface is positively charged when in contact with $\mathrm{H}_{2} \mathrm{SO}_{4}$ [37]. Because of the accumulation of positive charges at the interface, sulfate ions get adsorbed here because of electrostatic interaction, leading to the formation of the electrical double layer. These negative charges will allure protonated FMHC for adsorption. In this way, protonated FMHC gets electrostatically adsorbed on mild steel, which was previously covered with sulfate ions. Likewise, at cathodic regions also, protonated FMHC gets adsorbed thereby decreasing the rate of hydrogen evolution [38, 39]. Schematic illustration of corrosion inhibition mechanism of FMHC is depicted in Fig. 8.

\subsection{Quantum chemical study}

As per Pearson's Hard Soft Acid-Base (HSAB) theory, the energy gap is difference between the highest occupied molecular orbital $\left(E_{\mathrm{HOMO}}\right)$ and lowest unoccupied molecular orbital ( $\left.E_{\text {LUMO }}\right)$ of the inhibitor molecule [40]. Further, $E_{\mathrm{HOMO}}$ is directly connected to ionization energy and $E_{\text {LUMO }}$ is directly linked to electron affinity. Hence liability of a molecule toward electrophilic attack is designated by $E_{\text {Hомо }}$, while the vulnerability of a molecule toward nucleophilic attack is shown by $E_{\text {LUMO }}$ [41]. Optimized
Fig. 8 Schematic representation of the mechanism of corrosion inhibition by FMHC

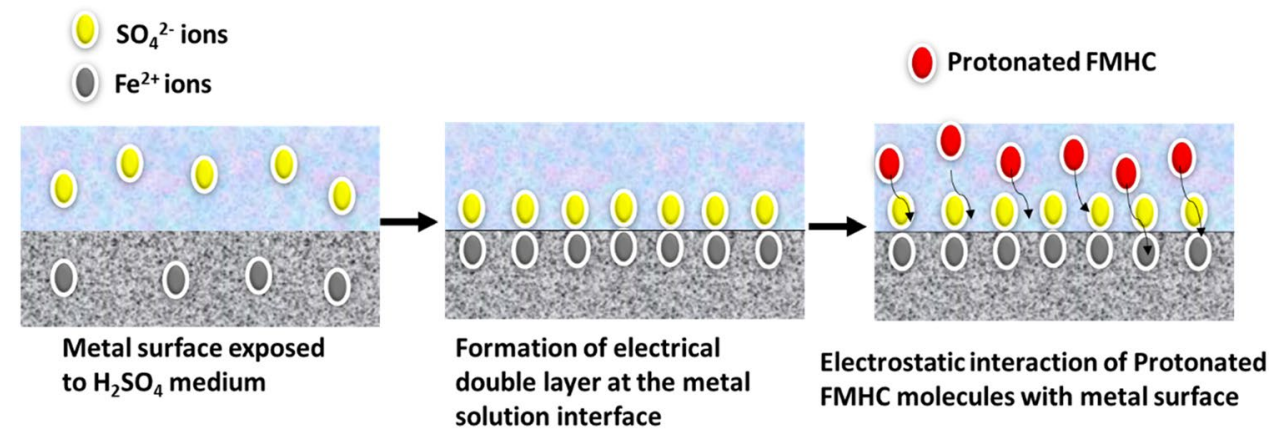


structures of FMHC and frontier orbital electron density distribution for neutral FMHC are shown in Fig. 9.

FMHC gets protonated in an aqueous acidic medium and involves in the physical adsorption process. Optimized structure and frontier orbital electron density distribution for protonated FMHC are shown in Fig. 10.

It becomes essential to know the electron population or electron density distribution within the inhibitor molecule. The preferred site for protonation of FMHC is heteroatom with remarkably high negative Mulliken charges. $[42,43]$. Mulliken charge distribution in various heteroatoms present in FMHC is given in Fig. 11 and Table 5.

Table 6 reports the various parameters of the quantum chemical study of FMHC (for neutral and protonated molecules) [44-47].
When $E_{\mathrm{HOMO}}$ of the neutral molecule is associated with that of protonated FMHC, there is a diminution in the value showing that electron-donating ability decreased significantly after protonation. Further, the $\mathrm{E}_{\mathrm{LUMO}}$ value also reduced to a significant extent suggesting that the electron-accepting capacity of the FMHC increased. After protonation, the global electronegativity $(\chi)$ increased twofold. Electrophilicity index $(\omega)$ increased, and nucleophilicity $(\epsilon)$ decreased to a large extent in the case of protonated FMHC. This led to stable layer formation on the surface of mild steel as a decrease in the energy gap $\left(\Delta E\right.$, ) between $E_{\mathrm{HOMO}}$ and $E_{\mathrm{LUMO}}$. For a neutral FMHC, the fraction of electron transferred $(\Delta N)$ is 0.26 , whereas for protonated FMHC molecule, it is -1.63 . This suggested that a neutral molecule can give electrons, whereas after protonation, its electron giving capacity is reduced and its tendency to
Fig. 9 Optimized structure and frontier orbital electron density distribution for neutral FMHC

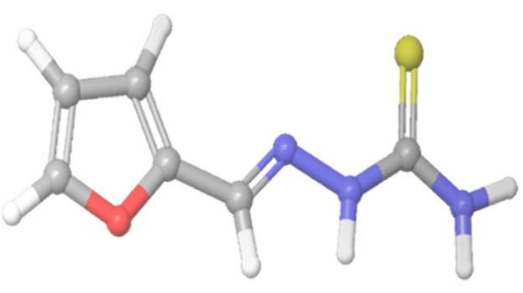

NEUTRAL OPTIMIZED STRUCTURE

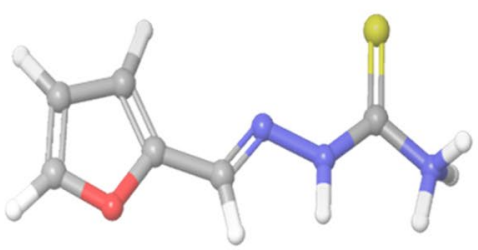

PROTONATED OPTIMIZED STRUCTURE

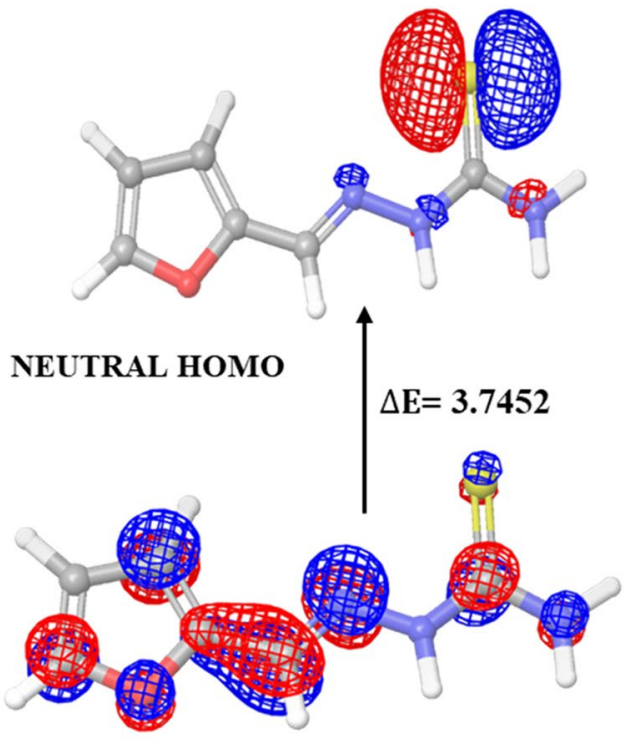

NEUTRAL LUMO

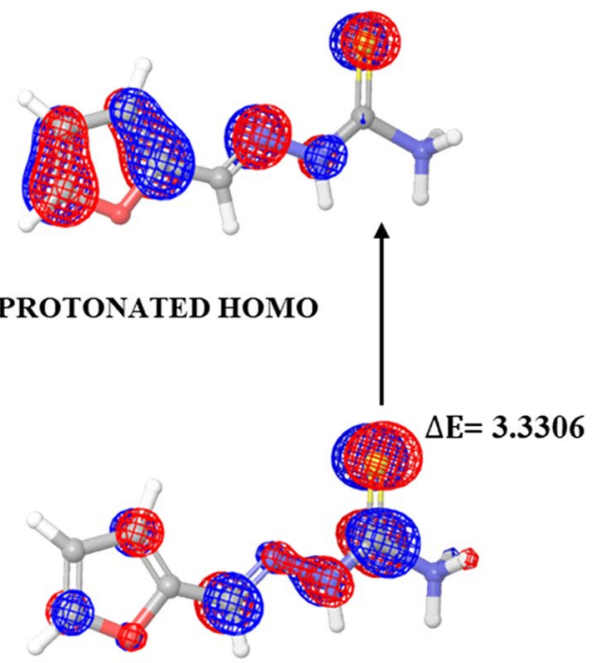

PROTONATED LUMO 
Fig. 11 Mulliken charge distribution

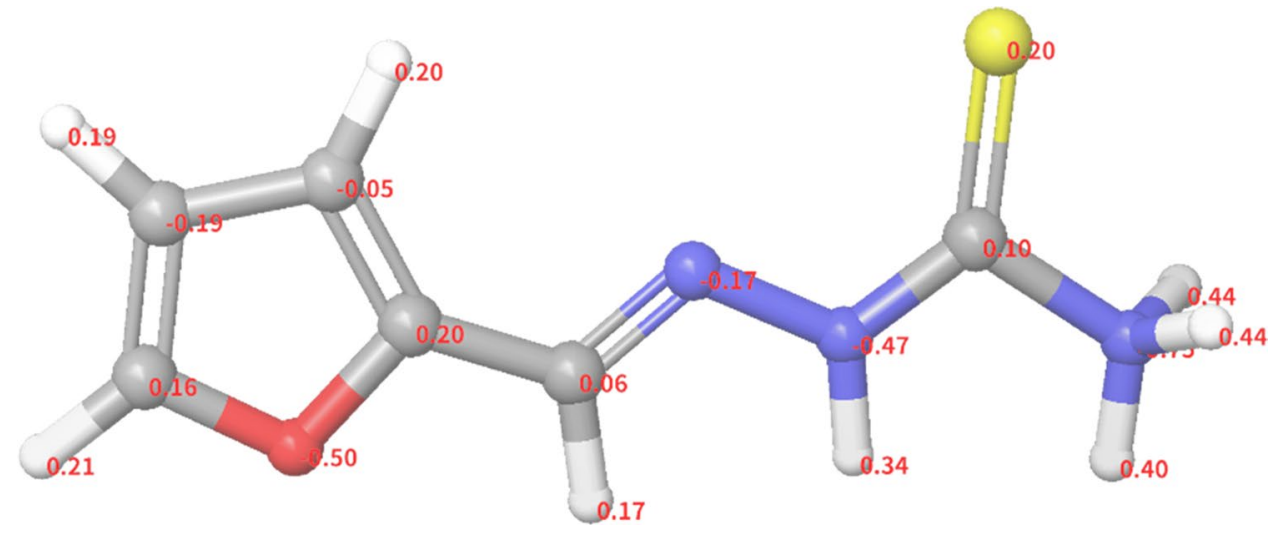

Table 5 Mulliken charges on heteroatoms of FMHC

\begin{tabular}{llllll}
\hline Mulliken charge & $\mathrm{O}(1)$ & $\mathrm{N}(7)$ & $\mathrm{N}(8)$ & $\mathrm{N}(10)$ & $\mathrm{S}(7)$ \\
\hline Neutral & -0.521 & -0.131 & -0.521 & -0.721 & -0.08 \\
Protonated & -0.500 & -0.166 & -0.469 & -0.745 & 0.19 \\
\hline
\end{tabular}

receive electrons increased many folds [44]. This again reaffirmed the physisorption of protonated FMHC molecules onto the surface of mild steel.

The dipole moment $(\mu)$ of the neutral FMHC is 1.150 Debye. After protonation, the dipole moment is 8.811 Debye. The large increase in the value of dipole moment for protonated molecule compared to that of water molecule confirmed its physical adsorption on metallic surface replacing water molecule [48].

\subsection{Surface morphology studies}

The impact of FMHC on corrosion of mild steel was evaluated by recording the SEM pictures. Mild steel was immersed in $0.5 \mathrm{M} \mathrm{H}_{2} \mathrm{SO}_{4}$ for $3 \mathrm{~h}$ with and without inhibitor. Figure 12a shows the pits because of the destructive activity of $0.5 \mathrm{M}$ $\mathrm{H}_{2} \mathrm{SO}_{4}$ on the mild steel surface with cracks and unpleasant, uneven, in homogeneous surface. Figure $12 \mathrm{~b}$ depicts steel surface after immersion in $0.5 \mathrm{M} \mathrm{H}_{2} \mathrm{SO}_{4}$ containing $2.5 \times 10^{-4} \mathrm{M}$ FMHC. It is quite evident that surface has become relatively smooth in large area due to the adsorption of FMHC.

\section{Conclusions}

1. The effectiveness of FMHC increased with its concentration and lessened at elevated temperatures.

2. FMHC performed as a moderate mixed type of inhibitor, endured physical adsorption, and adapted Langmuir's adsorption isotherm.

3. FMHC showed inhibition efficiency of $60 \%$ at concentration of $2.5 \times 10^{-4} \mathrm{M}$ at $303 \mathrm{~K}$.

4. Surface studies confirmed the adsorption of FMHC on the metal.

5. Quantum chemical calculations supported the mechanistic aspect of corrosion.
Table 6 Quantum chemical parameters of the neutral and protonated FMHC

\begin{tabular}{lllllllllll}
\hline & $\mathrm{E}_{\text {номо }}$ & $\mathrm{E}_{\mathrm{LUMO}}$ & $\Delta \mathrm{E}$ & $\chi$ & $\eta$ & $\sigma$ & $\omega$ & $\varepsilon$ & $\Delta N$ & $\mu$ \\
\hline Neutral & -5.3850 & -1.6398 & 3.7452 & 3.5124 & 1.8726 & 0.5340 & 1.6470 & 0.6071 & 0.26 & 1.150 \\
Protonated & -9.4449 & -6.1143 & 3.3306 & 7.7796 & 1.6653 & 0.6004 & 9.0857 & 0.110 & -1.63 & 8.811 \\
\hline
\end{tabular}

Units: Energy—eV; $\mu-$ Debye; $\sigma-\mathrm{eV}^{-1}$ 

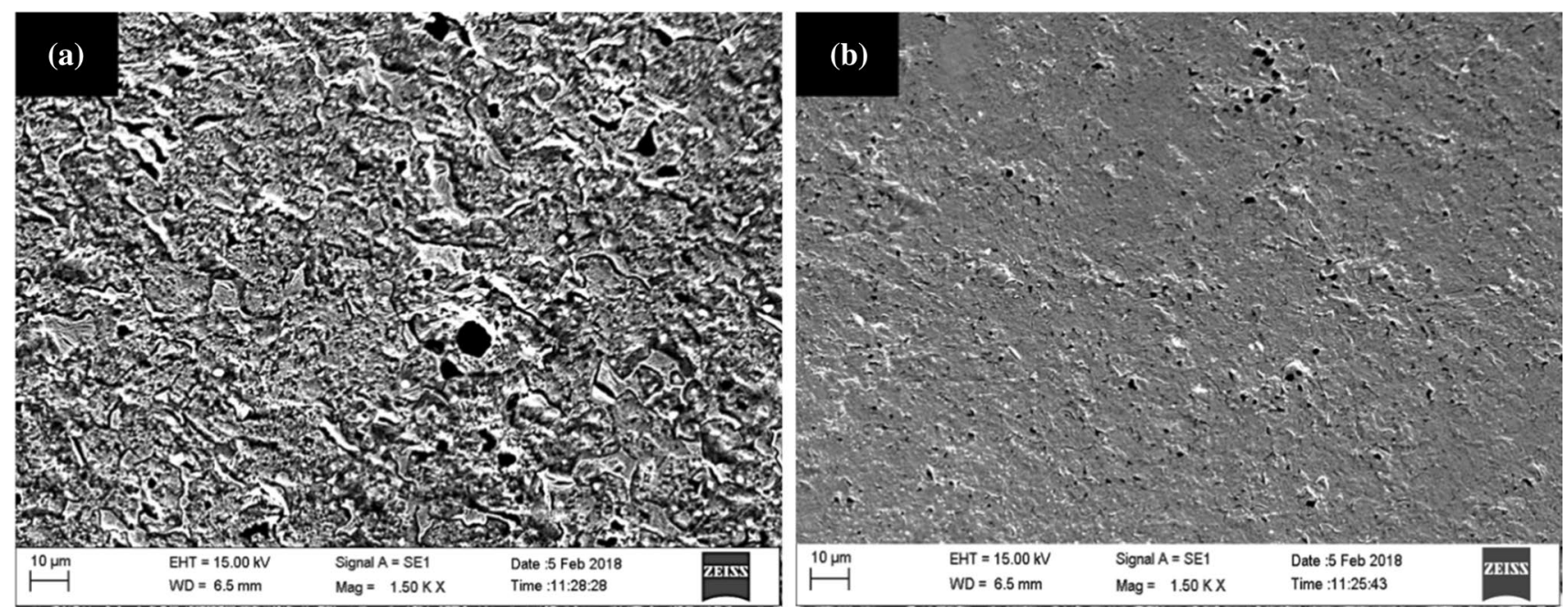

Fig. 12 SEM images: a MS $+0.5 \mathrm{M} \mathrm{H}_{2} \mathrm{SO}_{4}$ and b $\mathrm{MS}+0.5 \mathrm{M} \mathrm{H}_{2} \mathrm{SO}_{4}+2.5 \times 10^{-4} \mathrm{M}$ of FMHC

Acknowledgements The authors acknowledge the laboratory facility extended by the Department of Chemistry, MIT, MAHE. The authors would also like to thank Dr. Padmalatha Rao and Ms. Mikitha Pais for the fruitful discussion and support given during the preparation of the manuscript.

Funding Open access funding provided by Manipal Academy of Higher Education, Manipal. Not applicable.

\section{Declarations}

Conflict of interest On behalf of all authors, the corresponding author claims no conflict of interest.

Open Access This article is licensed under a Creative Commons Attribution 4.0 International License, which permits use, sharing, adaptation, distribution and reproduction in any medium or format, as long as you give appropriate credit to the original author(s) and the source, provide a link to the Creative Commons licence, and indicate if changes were made. The images or other third party material in this article are included in the article's Creative Commons licence, unless indicated otherwise in a credit line to the material. If material is not included in the article's Creative Commons licence and your intended use is not permitted by statutory regulation or exceeds the permitted use, you will need to obtain permission directly from the copyright holder. To view a copy of this licence, visit http://creativecommons.org/licenses/by/4.0/.

\section{References}

1. Prabhu RA, Venkatesha TV, Shanbhag AV, Praveen BM et al (2008) Quinol-2-thione compounds as corrosion inhibitors for mild steel in acid solution. Mater Chem Phys 108:283-289. https://doi.org/10.1016/j.matchemphys.2007.09.038

2. Narayan R (1993) An introduction to metallic corrosion and its prevention. Oxford and IBH Publishing Co, New Delhi

3. Sathiyanarayanan AS, Jeyaprabha C, Muralidharan S, Venkatachari G (2006) Inhibitionof iron corrosion in 0.5 Msulphuric acid by metal cations. Appl Surf Sci 252:8107-8112. https://doi. org/10.1016/j.apsusc.2005.10.028
4. Mercer AD (1994) Corrosion inhibition: principles and practice. In: Shreir LL, Jarman RA, Burstein GT (eds) Corrosion control. Butterworth Heinemann, Oxford

5. Revie W, Uhlig's (2000) Corrosion handbook, 2nd edn. Wiley, NewYork

6. Kumari P, Shetty P, Rao SA, Sunil D (2014) Corrosion inhibition and adsorption behaviour of (2E)-2-(3-hydroxy benzylidene) hydrazine carbothiamide on mild steel in $1 \mathrm{M} \mathrm{HCl}$. Rev Roum Chim 59(5):323-333

7. Saliyan R, Adhikari V (2008) Quinolin-5-ylmethylene-3-\{[8(trifluoromethyl)quinolin-4- yl]thio \}propanohydrazide as an effective inhibitor of mild steel corrosion in $\mathrm{HCl}$ solution. Corros Sci 50:55-61. https://doi.org/10.1016/j.corsci.2006.06.035

8. Mohan P, Arunsunai KK, Paruthimal KG, Muralidharan VS (2012) N'- (4-Methoxy benzylidene)benzo hydrazideas effective corrosion inhibitor for mild steel in $1 \mathrm{M} \mathrm{HCl}$. Asian J Chem 24:5821-5823

9. Fouda AS, Mohamed MT, Soltan MR (2013) Role of some benzo hydrazide derivatives as corrosion inhibitorsfor carbon steel in $\mathrm{HCl}$ solution. J Electrochem Sci Technol 4:61-70. https://doi.org/ 10.5229/JECST.2013.4.2.61

10. Yadav M, Sinha RR, Kumar S, Bahadur I, Ebenso EE (2015) Synthesis and application of new acetohydrazide derivatives as a corrosion inhibition of mild steel in acidic medium: insight from electrochemical and theoretical studies. J Mol Liq 208:322-332. https://doi.org/10.1016/j.molliq.2015.05.005

11. Larabi L, Harek Y, Benali O, Ghalemb S (2005) Hydrazide derivatives as corrosion inhibitors for mild steel in $1 \mathrm{M}$ HC. Prog Org Coat 54:256-262. https://doi.org/10.1016/j.porgcoat.2005.06.015

12. Khaled KF, Elhabib OA, El-mghraby A, Ibrahim OB, MagdyIbrahim AM (2010) Inhibitive effect of thiosemicarbazone derivative on corrosion of mild steel in hydrochloric acid solution. J Mat Environ Sci 3:139-150

13. El-Shafei AA, Moussa MNH, El-FarAA (2001) The corrosion inhibition character of thiosemicarbazide and its derivatives for C-steel in hydrochloric acid solution. Mat Chem Phys 70:175180. https://doi.org/10.1016/s0254-0584(00)00496-x

14. Saliyan R, Adhikari V (2009) Corrosion inhibition of mild steel in acid media by quinolinylthiopropanohydrazones. Indian J Chem Technol 16:162-174

15. Goulart CM, SouzaAE HCAM, Rodrigues CJF, Maciel MAM (2013) Experimental and theoretical evaluation of semicarbazones 
and thiosemicarbazones as organic corrosion inhibitors. Corros Sci 67:281-291. https://doi.org/10.1016/j.corsci.2012.10.029

16. Emregül KC, Hayvalı M (2004) Studies on the effect of vanillin and protocatechualdehyde on the corrosion of steel in hydrochloric acid. Mater Chem Phys. https://doi.org/10.1016/j.match emphys.2003.08.030

17. Renata BO, Elaine MSF, Rodrigo PPS, Anderson AA, Antoniana UKC (2008) Synthesis and antimalarial activity of semicarbazone and thiosemicarbazone derivatives. Eur J Med Chem 43:19831988. https://doi.org/10.1016/j.ejmech.2007.11.012

18. Uhlig HH, Revie RW (2008) Corrosion and corrosion control, 4th edn. Wiley, Hoboken

19. Prakashaiah BG, Vinaya Kumara D, Anup Pandith A, Nityananda Shetty A, Amitha Rani BE (2018) Corrosion inhibition of 2024T3 aluminum alloy in $3.5 \% \mathrm{NaCl}$ by thiosemicarbazone derivatives. Corros Sci 136:326-338. https://doi.org/10.1016/j.corsci. 2018.03.021

20. Singh P, Ebenso EE, Olasunkanmi LO, Obot IB, Quraishi MA (2016) Electrochemical, theoretical, and surface morphological studies of corrosion inhibition effect of green naphthyridine derivatives on mild steel in hydrochloric acid. J Phys Chem C 120:3408-3419. https://doi.org/10.1021/acs.jpcc.5b11901

21. Verma C, Olasunkanmi LO, Ebenso EE, Quraishi MA, Obot IB (2016) Adsorption behavior of glucosamine-based, pyrimidinefused heterocycles as green corrosion inhibitors for mild steel: experimental and theoretical studies. J Phys Chem C 120:1159811611. https://doi.org/10.1021/acs.jpcc.6b04429

22. Ansari KR, Quraishi MA, Singh A, Ramkumar S, Obote IB (2016) Corrosion inhibition of $\mathrm{N} 80$ steel in $15 \% \mathrm{HCl}$ by pyrazolone derivatives: electrochemical, surface and quantum chemical studies. RSC Adv 6:24130-24141. https://doi.org/10.1039/ c5ra25441h

23. Yudhistira R, Kumari P, Sunil D, Shetty P, Rao SA (2019) Attenuation of acid corrosion of mild steel using a novel organic dye: electrochemical and surface measurements. Surf Eng Appl Electrochem 55:443-454

24. Khadiri A, Saddik R, Bekkouche K, Aouniti A, Hammouti B, Benchat N, Bouachrine M, Solmaz R (2016) Gravimetric, electrochemical and quantum chemical studies of some pyridazine derivatives as corrosion inhibitors for mild steel in $1 \mathrm{M} \mathrm{HCl} \mathrm{solu-}$ tion. J Taiwan Inst Chem Eng 58:552-564. https://doi.org/10. 1016/j.jtice.2015.06.031

25. Abd El-Maksoud SA, Fouda AS (2005) Some pyridine derivatives as corrosion inhibitors for carbon steel in acidic medium. Mater Chem Phys 93:84-90. https://doi.org/10.1016/j.matchemphys. 2005.02.020

26. Kumari P, Rao SA, Shetty P, Sunil D (2014) Corrosion inhibition and adsorption behavior of (2E)-2-(3-hydroxy-2-methoxybenzylidee hydrazine carbothioamide on mild steel in $0.5 \mathrm{HCl}$. Rev Roum Chem Phys 59(5):323-333

27. Li W, He Q, Jhang S (2008) Some new triazole derivatives as inhibitors for mild steel corrosion in acidic medium. J Appl Electrochem 38:289-290

28. Lagrenee M, Mernari B, Bouanis M, Traisnel M, Bentiss F (2002) Study of the mechanism and inhibiting efficiency of 3,5-bis(4methylthiophenyl)-4H-1,2,4-triazole on mild steel corrosion in acidic media. Corros Sci 44(3):573-588. https://doi.org/10.1016/ S0010-938X(01)00075-0

29. Kumari P, ShettyP RSA (2014) Corrosion inhibition effect of 4-hydroxy-N-[E-(1H-indole-2-ylmethylidene)] benzohydrazide. Int J Corros. https://doi.org/10.1155/2014/256424

30. Kumar P, Shetty AN (2013) Electrochemical investigation on the corrosion of $18 \% \mathrm{Ni} \mathrm{M} 250$ grade maraging steel under welded condition in sulfuric acid medium. Surf Eng Appl Electrochem $49: 253-260$
31. AnbarasiCM AuxiliaAJ (2016) Surface modification of carbon steel by hexanesulphonic acid- $\mathrm{Ni}^{2+}$ system and its corrosion study. Int J Chem Tech Res 9:218-225

32. Keles H, Keles M (2014) Electrochemical investigation of a Schiff base synthesized by cinnamaldehyde as corrosion inhibitor on mild steel in acidic medium. Res Chem Intermed 40:193-209

33. OguzieEE NVO, Enenebeaku CK, AkaleziCO OC (2008) Effect of hexamethylpararosaniline chloride (crystal violet) on mild steel corrosion in acidic media. Corros Sci 50:3480-3486

34. Migahed MA, MohammedHM A-S (2003) Corrosion inhibition of $\mathrm{H}-11$ type carbon steel in $1 \mathrm{M}$ hydrochloric acid solution by $\mathrm{N}$-propyl amino lauryl amide and its ethoxylated derivatives. Mater Chem Phys 80:169-175

35. Nada F, Atta FAM, Hamdi M, Hassaneen (2011) Electrochemical and antibacterial properties of $316 \mathrm{~L}$ stainless steel in acid medium containing different newly synthesized organic inhibitors. Int $\mathbf{J}$ Hydrog Eng 36(11):6462-6471

36. Fekry AM, Ameer MA (2010) Corrosion inhibition of mild steel in acidic media using newly synthesized heterocyclic organic molecules. Int J Hydrog Eng 34(14):7641-7651

37. Mallaiya K, Subramaniam R, Srikandan SS, Gowri S, Rajasekaran N, Selvaraj A (2011) Electrochemical characterization of the protective film formed by the unsymmetrical Schiff's base on the mild steel surface in acid media. Electrochimi Acta 56:3857-3863. https://doi.org/10.1016/j.electacta.2011.02.036

38. Popova A, Christov M, Raicheva S, Sokolova E (2004) Adsorption and inhibitive properties of Benzimidazole derivatives in acid mild steel corrosion. Corros Sci 46:1333-1350

39. de Oliveira RB, de Souza-Fagundes EM, Soares RPP Andrade AA, Krettli AU, Zani CL (2008) Synthesis and antimalarial activity of semicarbazone and thiosemicarbazone derivatives. Eur J Med Chem 43:1983-1988. https://doi.org/10.1016/j.ejmech.2007. 11.012

40. Gupta NK, Verma C, Salghi R, Lgaz H, Mukherjee AK, Quraishi MA (2017) New phosphonate based corrosion inhibitors for mild steel in hydrochloric acid useful for industrial pickling processes: experimental and theoretical approach. New J Chem 41:1311413129. https://doi.org/10.1039/c7nj01431g

41. Arukalam IO (2014) Durability and synergistic effects of KI on the acid corrosion inhibition of mild steel by hydroxypropyl methylcellulose. Carbohydr Polym 112:291-299. https://doi.org/ 10.1016/j.carbpol.2014.05.071

42. Gao G, Liang C (2007) Electrochemical and DFT studies of $\beta$-amino-alcohols as corrosion inhibitors for brass. Electrochim Acta 52:4554-4559. https://doi.org/10.1016/j.electacta.2006.12. 058

43. Hasanov R, Sadikoğlu M, Bilgiç S (2007) Electrochemical and quantum chemical studies of some Schiff bases on the corrosion of steel in $\mathrm{H}_{2} \mathrm{SO}_{4}$ solution. Appl Surf Sci 253:3913-3921. https:// doi.org/10.1016/j.apsusc.2006.08.025

44. Obot IB, Macdonald DD, Gasem ZM (2015) Density functional theory (DFT) as a powerful tool for designing new organic corrosion inhibitors: Part 1: an overview. Corros Sci 99:1-30. https:// doi.org/10.1016/j.corsci.2015.01.037

45. Geerlings P, De Proft F, Langenaeker W (2003) Conceptual density functional theory. Chem Rev 103:1793-1873. https://doi.org/ $10.1021 /$ cr990029p

46. Chauhan DS, Ansari KR, Sorour AA, Quraishi MA, Lgaz H, Salghi R (2018) Thiosemicarbazide and thiocarbohydrazide functionalized chitosan as ecofriendly corrosion inhibitors for carbon steel in hydrochloric acid solution. Int J Biol Macromol 107:1747-1757. https://doi.org/10.1016/j.ijbiomac.2017.10.050

47. Obot IB, Ebenso EE, Kabanda MM (2013) Metronidazole as environmentally safe corrosion inhibitor for mild steel in $0.5 \mathrm{M} \mathrm{HCl}$ : experimental and theoretical investigation. J Environ Chem Eng 1:431-439. https://doi.org/10.1016/j.jece.2013.06.007 
48. Idir B, Kellou-Kerkouche F (2018) Experimental and theoretical studies on corrosion inhibition performance of phenanthroline for cast iron in acid solution. J Electrochem Sci Technol 9:260-275

\section{Authors and Affiliations}

\section{R. Adinarayanan ${ }^{1}$ - P. Preethi Kumari ${ }^{1}$ - Suma A. Rao ${ }^{1}$ D}

$\triangle$ Suma A. Rao

suma.rao@manipal.edu
Publisher's Note Springer Nature remains neutral with regard to jurisdictional claims in published maps and institutional affiliations.
Department of Chemistry, Manipal Institute of Technology, Manipal Academy of Higher Education, Manipal 576104, India 